\title{
Instrumentation - the next generation needs an industry champion
}

\author{
PM Burton Geotechnics, New Zealand
}

\begin{abstract}
Consumer and industrial developments have led to the instrumentation of today, but how will we develop the instrumentation of tomorrow? Collaboration and connectivity in our profession is evident via the high participation of specialists at symposia such as Field Measurements in Geomechanics (FMGM) and via social media such as the Geotechnical and Structural Instrumentation and Monitoring (GSIM) group on LinkedIn. However, we do not have an international umbrella organisation, a specialist technical body that champions the cause of instrumentation. Such a body would allow our industry to best benefit from and harness advances and possibilities in technology. An international organisation would provide an excellent framework for the future. The paper reviews the current status and suggests scope and objectives for such an organisation.
\end{abstract}

\section{Introduction}

We can look back and see how consumer and industrial developments have led to the instrumentation of today, but how will we develop the instrumentation of tomorrow? This paper discusses both the technical development process and the culture of development and leadership in our profession with an assumption that we all want a vibrant and attractive profession in the future.

There are many examples of instrumentation that have originated from the development of consumer and industrial electronics. Our equipment suppliers have, to varying degrees, harnessed and transferred the ever cost-reducing technology to products with much lower sales quantities. How can we look to the future, identify the direction and ride the wave with minimal delays? What are we, as an industry, doing to collaborate with these high volume technology developers to benefit our profession?

There are also many examples of excellent collaboration occurring in our industry. How can we best herald these pathfinders and the work they do for the profession and ultimately our worldwide community? What can we do to help these leaders and ensure their ongoing efforts are recognised and encouraged? We are improving the safety and efficiency of projects small through to large but we need to promote this to all stakeholders and recognise excellence.

Collaboration and connectivity in our profession are highlighted with the high participation of specialists at symposia such as FMGM. The meeting of minds and sharing of experience is beneficial for all who participate. What are we going to do for the future? We have a dizzying array of experts in both technical and leadership roles gathered together and this is an ideal forum to discuss what the next development might be? How will we change from interactions at a rate of $1.3 \times 10^{\wedge} 8 \mathrm{~Hz}$ to an online world of constancy?

The theme of 'the next generation' requires us to talk further on how we can collaborate to encourage the students of today into an attractive and flourishing profession. We can look to other professions for ideas but what will we do?

Instrumentation specialists of the past have given us a great foundation through FMGM. Our future is in our hands and we will not only need to develop our leadership but concurrently act in ways that support the desired direction. If we want to encourage the experts of tomorrow toward a career in instrumentation, then we will need to both show leadership and develop our discipline with inspirational changes in how we work. 
There are clear recommendations and conclusions for linking the development of our products and services with the development of our people. The recommendations range in size, from personal steps through to worldwide developments requiring the collaboration of academic institutes, professionals, suppliers, stakeholders, contractors and other industries, as yet unknown.

This paper is written from the perspective of an instrumentation specialist in New Zealand. Although this region is highly developed in world terms, its remoteness to suppliers, transportation links and major international academic institutions poses significant challenges to providing best practice to our instrumentation market. Some of the challenges may be common worldwide; however, it is appreciated that this may vary from country to country.

\section{$2 \quad$ In the year 2015}

As a practitioner in the instrumentation industry, I hold memberships with technical and professional organisations. These organisations have mandates in their specific areas such as geotechnical or civil engineering testing; however, the instrumentation discipline is somewhat of an outlier to the primary focus of these organisations.

There are many ways to connect with others in our industry and these are fast becoming more easily managed with the rise of social media. We have an excellent symposium event in FMGM, held every four years, which provides a forum for specialists to meet.

However, we do not have an international specialist technical organisation that champions the cause of instrumentation. There are excellent national technical organisations that accept instrumentation specialists into their fold, but they are not the consistent touch point that would allow our industry to harness the enthusiasm, energy and developmental desire that specialists in our field could really benefit from in the creation of a specialist technical society.

\section{A sense of belonging}

I have grown over the years with my involvement in, and founding of, national organisations in New Zealand associated with geotechnical/civil engineering and testing along with work in our professional engineering consultancy organisation.

However, there is one outstanding organisation that I would like to see created and developed, and that is an international group of instrumentation specialists.

In comparison to many technical organisations, the FMGM symposia are an anomaly compared to how common voluntary organisations work. I suggest that many 'functioning' professional societies have an organisation but lack symposium gatherings, whereas the FMGM symposia organisation creates excellent events but does not have a mandate for industry development in the intervening years. That is not to say that excellent events and forums do not exist, they certainly do and they are mentioned later in this paper.

\section{$4 \quad$ The rise of technology}

Over the past century we have seen a significant change in the technology available in both our home and business lives. The communication devices we now use have transformed the way we live and work. The mass production of consumer electronic components and products has significantly increased availability and subsequently driven prices down. This in turn has allowed specialist industries such as the instrumentation industry to access cheaper and highly developed tools for use in lower production rate products.

We have not only seen the rise of cheaper hardware but the expansion of electronic memory modules into smaller and smaller packages. This has allowed our industry to benefit from the ability to store more data and collect more data. This may be seen by some as a significant challenge, adding complexity where it may not be needed; however, it is now possible and this is the key point. 
In time we will see the technology developments that are classed as news items becoming reality in our workplace. The rise of 3D printing will allow us to custom build our instruments when and how we want. The Amazon drones of today will be the landslide monitoring solutions of tomorrow. This may seem years away now, but we must remember that the humble mobile phone of the 90s struggled with text messaging and we now have instruments streaming near real-time complex data through wireless (mobile phone based) modems to Web interfaces allowing us to react to alarms from the other side of the world.

The big question is what will be next and then how do we, as an industry, find out about these emerging technologies, appraise their transferability and then harness them for the benefit of all?

\section{$5 \quad$ Connectivity in our industry}

The FMGM symposia have been successfully run for our industry since 1983 and some may argue earlier events were the forerunners. These symposia provide an excellent forum for our industry to meet, listen to developments, hear of others case studies and network with suppliers and practitioners. Through the hard work of many, voluntarily in the majority of cases, we have had a four yearly forum that served us well.

There have been Websites for the more recent symposia, aimed at those individual symposia along with the fmgm.no site that was an excellent use of web technology when it was developed in 2001. The FMGM organisation has worked in developing the symposium events, but does not currently have an advertised over-arching mandate for ongoing development with associated communication.

The rise of Linkedln has seen the industry provide further connectivity to interested parties. An example of an excellent use of modern social media is the Geotechnical and Structural Instrumentation and Monitoring group on Linkedln that now counts its members in excess of 2,000. Although smaller but no less important we also have the Geotechnical and Structural Instrumentation group on LinkedIn. The ability for anyone with interest to participate in discussion, in whatever time zone they reside, with like-minded individuals and organisations from around the world has opened up our ability to encourage conversations that were once seemingly impossible. Essential to these forums is the involvement of the significant members in our community, the text book writers of yesterday, encouraging and sharing knowledge for the benefit of our community.

The instrumentation specialists of tomorrow are still at school and university and use a much greater array of different communication tools than we use in our workplaces. Much of the time this is appropriate as social media, which gives a clue about this in the term's name. It is generally for social use. This may be the case, but these future FMGM attendees will expect a different way of working, and will be very surprised if we as an industry are not using technology and systems that they have been using on an hourly basis throughout their lives.

We have an opportunity to harness the energy of our graduate attendees, mixing that with the experience of our founding members, creating a living organisation that exists online whenever you want it. Joining existing specialist groups together will provide the world with a touch point for instrumentation specialists when communicating with other specialists in the engineering and technology disciplines.

We can work with the successes we have already seen in creating connectivity for our members and build on that.

\section{$6 \quad$ Learning and development}

We have all learnt about our specialist industry through many different ways such as basics through school, progressing to technical colleges, universities, apprenticeships, internships, on the job training, training courses and of course some trial and error. The availability of each of these options can vary dependent on our location, but it should be said that trial and error would probably feature quite highly amongst us. 
There is a place in our career development for all types of learning environments, but what as an industry are we doing to create new opportunities for learning in new and different ways? Our industry's future lies with our ability to create these opportunities and be open to the evolution of our next generation.

We have specialists who gather to provide formal courses to a worldwide audience. These are an excellent way for interested parties from around the world to hear from the leaders of our industry, Natural Hazards Control and Assessments (NHAZCA) are to be commended for their leadership in this area. It should also be noted that various other organisations and suppliers are supporting this event in various ways and this collaboration is a great example of how our industry is developing.

These events are currently held on an annual basis in Italy and the promotional information states that this is probably the unique opportunity to increase expertise about geotechnical and structural monitoring and at the same time have a beautiful cultural, historical and taste experience in one of the most attractive tourist places of the world. It is of course unique that this event is held on an annual basis in a very beautiful part of the world, but we should be considering hosting this and other events in other parts of the world which would present additional learning opportunities.

\section{Instrumentation awareness in university}

In my experience the world of geotechnical instrumentation became apparent whilst in the workforce. I appreciate that there are many who continue with further education in the area of instrumentation, but most undergraduates in my geographic area have limited or no exposure to the instruments of today.

I have spent many hours teaching graduate engineers about the options available to them for both structural and geotechnical instrumentation. This goes further to include the principles around why we should monitor and what benefits are to be gained by the various stakeholders. I direct engineers to FMGM papers which on the whole cover most of the topics requested. These papers, used in conjunction with text books and 'Geotechnical News' editions, both old and new, provide undergraduates and graduates alike with a source of enlightenment and reference.

This works well for people I share connections with but what about people who are searching online? A simple google search will easily show us who the main suppliers of instruments are from all parts of the world, but students do not necessarily want suppliers, they will usually be looking for references, repositories and connections to published works and how to connect with the experts. This is currently a shortcoming of our industry and we could improve.

\section{Create an international organisation}

My attendance at the FMGM symposium is a highlight of my conference schedule every four years, and Sydney was no exception. I am very impressed with all of the activities that occur around the world helping to develop our industry and a significant proportion of that work carried out on a voluntary basis. We have seen great steps forward in the provision of online forums, learning and development and opportunities for academia to mix with practitioners.

I would like to recommend that the current and upcoming FMGM committees strongly consider how we might work towards engaging in discussion prior to the next FMGM event. This engagement of interested parties should focus on the creation of an international organisation. In reality, this may take some time to develop, but if individuals in their own geographic regions gather interested parties and align with professional organisations in their own territories by FMGM 2019 we should have the beginnings of a distributed network of specialist instrumentation organisations.

To this end I would like to recommend that either the organising committee for the next event include these duties in their scope, or they delegate and track progress to another group who are enthused and willing to develop this concept.

The scope and objectives of an international society could include: 
- The promotion of high standards in the field measurement of geomechanics for the benefit of the engineering industry and society as a whole.

- To encourage the collaboration and exchange of ideas for practitioners worldwide.

- To encourage learning and development at all levels in field measurement of geomechanics.

The scope of an international organisation would probably be limited to the policy, governance, guidance and encouragement of regional activities. However, this would provide collective impetus to create living breathing technical societies that we can all belong to and develop our own future. This will allow many of the challenges listed in this paper to be addressed in the most appropriate ways for each individual territory whilst providing an over-arching direction, using the best people our industry has to offer.

The scope of territorial societies would be dependent on the participants but could include:

- Continuous improvement of instrumentation standards.

- Encouraging instrumentation as tools for safer work places.

- Providing a touch point and collaboration for other organisations/societies/industry/academia.

- Promoting instrumentation as a career.

- Promoting high quality training to members.

- Representation to regulatory authorities.

- Creation of student awareness resources.

- Communicating the developments of the suppliers with feedback loops.

All of these possibilities can be developed within the current available frameworks and organisation structures. The gathering of individuals for international meetings can coincide with currently available courses/fora allowing the formalising of what is already a keen and enthused group of experts in our field.

The abovementioned actions are not insignificant in size and will require the efforts of many to achieve. It is important for all of us to remember that we can play our part in this development no matter how small or big we feel our commitment to this advancement is.

The addition of new initiatives will greatly strengthen our position for the future, seeking to both develop the people and the technology that we work with in commercial and academic surroundings. I would like to see a higher frequency of interaction than $1.3 \times 10^{8} \mathrm{~Hz}$. The future is a place we can try to predict, with some success at times, but it is also a place we create through the actions and decisions we make now.

\section{$9 \quad$ Acknowledgement}

I firstly thank all current and prior FMGM organising committees and participants. These gatherings have provided an excellent platform for growth and development to me and many others in our industry.

Further thanks go to key figures that have influenced my work in instrumentation: John Dunnicliff, for his continual encouragement of all matters instrumentation and Elmo Di Baggio, for his http://www.fmgm.no/ reference material and his feedback to the wider community.

The efforts of these individuals Daniele Cravino, Simone Desiderati to create the LinkedIn GSIM community and Vijay Mishra, Jose Luis Aguilar Perez for the LinkedIn Geotechnical and Structural Instrumentation community. These leaders, along with the active participants, have created links that were previously not possible.

I also thank the following organisations that are local to my work: New Zealand Geotechnical Society (NZGS), Civil Engineering Testing Association of New Zealand (CETANZ), and the Association of Consulting Engineers New Zealand (ACENZ). My involvement and learning through these groups have provided me with skills, experience and insight around the provision of active industry organisations. 
